\title{
OXIDATION BEHAVIOR OF TWO NICKEL-BASE SUPERALLOYS USED AS ELEVATED TEMPERATURE VALVES IN SPARK IGNITED ENGINES AND DIESEL EXHAUST RECIRCULATION (EGR) APPLICATIONS
}

\author{
S. Sinharoy and S. L. Narasimhan \\ Eaton Corporation - Engine Air Management Operations; 19218 B Drive South; Marshall, MI 49068, USA
}

Keywords: Isothermal oxidation, Oxide formation kinetics, Internal combustion engine

\begin{abstract}
With trends towards higher performance, fuel economy and natural resource conservation, alternative fuels being considered by the automotive industry pose special demands on internal combustion engine (ICE) exhaust valve materials. Similar demands are expected in exhaust gas recirculation (EGR) systems for gasoline ICEs and now being introduced in heavy-duty diesel engines. With application of high temperature combustion fuels such as propane and hydrogen, one of the key requirements of an exhaust valve material - oxidation resistance, is discussed in this study for two nickel-base superalloys. The relative oxidation behavior was evaluated by weight gain and depth of oxide penetration measurements. The study on the two alloys revealed that: (a) Oxidation behavior followed the classic $\mathrm{Cr}_{2} \mathrm{O}_{3}$ formation kinetics (b) Presence of cobalt as an alloying element significantly influences oxidation
\end{abstract}

\section{Introduction}

The use of nickel-base superalloys as internal combustion engine exhaust valve materials has increased significantly in the past few years as a result of demands made on valves through increasing stress levels or operating temperatures or both ${ }^{[1]}$. From a corrosion standpoint, exhaust valve materials used in ICEs are subjected to high temperature oxidizing environments. Typically, combustion environments in spark- ignited gasoline engines tend to be devoid of sulfur-based compounds and hence, oxidation resistance rather than sulfidation-accelerated corrosion resistance (also known as hot corrosion resistance), is an important criteria used in selection of exhaust valve materials ${ }^{[2]}$. In engines where acidic attack is involved, nickel-base alloys provide superior corrosion resistance.

While superalloys used in today's gasoline engines have excellent oxidation resistance and high temperature strength at current operating temperatures, there is a growing need for alloys that will be able to function at operating temperatures in excess of $800{ }^{\circ} \mathrm{C}$ and retain adequate oxidation resistance and fatigue strength. This trend to move towards higher operating temperatures is becoming more apparent as several automotive original equipment manufacturers (OEMs) continue to develop alternative fuel engines such as compressed natural gas $(\mathrm{CNG})$, propane and hydrogen-fueled internal combustion engine vehicles. A typical solid stem exhaust valve temperature distribution for a spark ignition engine is shown in Figure 1. The projected temperature distribution for a spark ignition engine that would use an alternative fuel resulting in higher exhaust valve temperatures is also depicted in the same figure. Apart from high temperatures arising from the use of hydrogen fuels, significant operating temperature increase can also result due to use of near stoichiometric fuel-air combustion and EGR for emission reduction and by the use of turbo-boosting systems in land and air vehicles powered by ICEs. In this article, oxidation behavior of two nickel-base superalloys, Nimonic $90^{\mathrm{TM}^{*}}$ and Pyromet $751^{\mathrm{TM}^{* *}}$ (similar to Inconel $751^{\mathrm{TM}^{*}}$ ), at $870{ }^{\circ} \mathrm{C}$ and $930{ }^{\circ} \mathrm{C}$ are presented and discussed. Inconel 751 is a commonly used nickel-base exhaust valve superalloy used in both gasoline and diesel ICEs, while Nimonic 90 has been primarily limited to heavy-duty diesel applications for higher fatigue strength. This study was undertaken to evaluate an appropriate alloy to meet the challenges of high temperature oxidation resistance demands of alternate fuel engine exhaust valves and diesel EGR valves.

It is well known that oxidation in high performance alloys can lead to dealloying and loss of surface strength and ultimately crack initiation and failure. Isothermal oxidation tests of coupons at elevated temperatures in air have been a common way of trying to evaluate oxidation in internal combustion engines. Although oxidation in air does not exactly simulate the combustion environment in the spark ignited engines, the high partial pressure of oxygen present in air represents a more severe form of oxidizing environment than the combustion environment.

\section{Experimental Procedures}

Bars of Nimonic 90 and Pyromet 751 used in this study were received in the hot-rolled and ground condition. Typical alloy compositions of the materials are given in Table I. Both materials were then solution treated and double-aged. Subsequently, cylindrical specimens measuring $25 \mathrm{~mm}$ in diameter and $12.7 \mathrm{~mm}$ in height were machined from the heat-treated bars. The original dimensions, along with the weight were accurately measured for each specimen prior to testing. Isothermal oxidation tests in static air were performed in a laboratory furnace at $870{ }^{\circ} \mathrm{C}$ and $930{ }^{\circ} \mathrm{C}$. Weight measurements and oxidation attack depth measurements were performed at intervals of 100 hours, 200 hours, 300 hours, 350 hours, 400 hours, 450 hours and 500 hours.

Oxidation severity was assessed by measuring the most severe attack depth in a given field of view using a light optical microscope, and by averaging over three separate measurements. Measurement of scale thickness was intentionally avoided to prevent inconsistency in attack depth determination. Two methods were used to make the attack depth measurements, depending on the severity of attack: (a) For shallow attack, ranging from approximately $0.01 \mathrm{~mm}$ to $0.03 \mathrm{~mm}$, measurements were taken

\footnotetext{
* Nimonic 90 and Inconel 751 are trademarks of Special Metals Corporation

** Pyromet 751 is a trademark of Carpenter Technology Corporation
} 
directly from optical micrographs with a magnification of 500x. (b) For severe oxidation attack, where the original diameter is no longer smooth or intact and cannot be used as a reference surface, an image analyzing system was used to measure the outer diameter associated with oxidation attack. Since the original diameter, was accurately measured prior to test, total attack depth was calculated by simple geometry. If the original diameter is $d_{o}$ and $d$ is the diameter measured at a location with the most severe attack, then the attack depth, $a$, was calculated as:

$$
a=\frac{d-d_{o}}{2}
$$

Weight measurements after oxidation exposure, were performed after the samples were cooled to room temperature. Specimens were characterized using light optical microscope and scanning electron microscope (SEM)/energy dispersive X-ray (EDX) spectroscopy techniques.
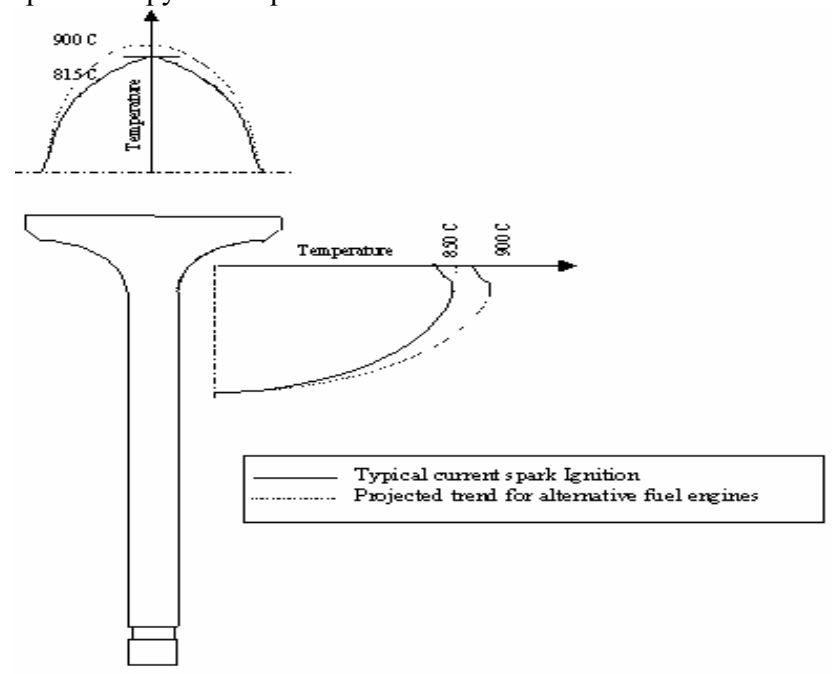

Figure 1 - Temperature distribution (current spark ignition gasoline and projected trend for alternative fuel engines) in exhaust valve

Table I. Alloy composition (wt \%) used in oxidation tests

\begin{tabular}{|c|c|c|}
\hline Element & Nimonic 90 & Pyromet 751 \\
\hline \hline Chromium & 19.5 & 15.5 \\
\hline Cobalt & 18 & 0.04 \\
\hline Iron & - & 8.3 \\
\hline Titanium & 2.4 & 2.3 \\
\hline Aluminum & 1.4 & 1.2 \\
\hline Niobium + Tantalum & - & 0.93 \\
\hline Molybdenum & - & 0.15 \\
\hline Carbon & 0.07 & 0.04 \\
\hline Zirconium & 0.07 & 0.008 \\
\hline Boron & 0.006 & 0.003 \\
\hline Sulfur & $<0.001$ & $<0.001$ \\
\hline Nickel & Balance & Balance \\
\hline
\end{tabular}

\section{Results and Discussions}

Weight change per unit area during isothermal oxidation in air was plotted as a function of exposure time at $870{ }^{\circ} \mathrm{C}$ and $930{ }^{\circ} \mathrm{C}$ as shown in Figure 2. Nimonic 90 and Pyromet 751 behaved in a similar manner at $870{ }^{\circ} \mathrm{C}$, with the rate of weight change appearing to stabilize after about 300 hours. Figure 2 shows that the rate of weight change due to oxidation at $930{ }^{\circ} \mathrm{C}$ is considerably higher for both the alloys compared to $870{ }^{\circ} \mathrm{C}$ exposure. Nimonic 90 and Pyromet 751 appear to exhibit similar trends in weight change with exposure time at the higher temperature, though the oxidation of Nimonic 90 is more severe after exposure time of 350 hours and 400 hours at $930{ }^{\circ} \mathrm{C}$.

Weight change per unit area during an isothermal oxidation process is expected to follow a relationship of the form:

$$
\left(\frac{\Delta W}{A}\right)^{2}=K p \cdot t
$$

where $\Delta W / A$ is the weight change per unit area, $t$ is the exposure time at a particular temperature and $K_{p}$ is the isothermal rate constant. A least-squares analysis of $870{ }^{\circ} \mathrm{C}$ and $930{ }^{\circ} \mathrm{C}$ data using Eq. [2] for the two materials resulted in determination of the isothermal rate constants as shown in Table II. The isothermal rate constant, $K_{p}$, of Nimonic 90 and Pyromet 751 are similar at 870 ${ }^{\circ} \mathrm{C}$. At $930{ }^{\circ} \mathrm{C}$, the $K_{p}$ of Pyromet 751 is $1 / 3$ of that of Nimonic 90 . The $K_{p}$ values determined in this evaluation were compared with previously determined $K_{p}$ values for aluminum oxide and chromium oxide found in literature on oxidation kinetics of superalloys ${ }^{[3,4,5,6,7]}$. Based on this comparison, the oxidation of Nimonic 90 and Pyromet 751 are seen to favor $\mathrm{Cr}_{2} \mathrm{O}_{3}$ formation kinetics. In addition to the determination of the isothermal rate constants, EDX analysis was also used on the Nimonic 90 and Pyromet 751 samples exposed at $870{ }^{\circ} \mathrm{C}$ and $930{ }^{\circ} \mathrm{C}$ to determine the nature of the oxides. The EDX analysis confirmed the formation of $\mathrm{Cr}_{2} \mathrm{O}_{3}$ as the primary oxidation mechanism at these temperatures.

In conjunction with weight change measurements, severity of the oxidation attack was also determined by measuring the maximum depth of attack. It should be stated that the oxidation severity as determined in this evaluation reflects a combination of metal loss and maximum metal affected. Figure 2 shows that the severity of oxidation attack at $930{ }^{\circ} \mathrm{C}$ for Nimonic 90 was higher than that of Pyromet 751 by about $30 \mu \mathrm{m}$. At $870{ }^{\circ} \mathrm{C}$, the oxidation severity was observed to be more for Nimonic 90 than Pyromet 751 , though the difference was only $10 \mu \mathrm{m}$. The observations made on weight change measurements along with oxidation severity measurements, show that oxidation in Nimonic 90 is more severe than Pyromet 751 at $930{ }^{\circ} \mathrm{C}$ after about 300 hours of exposure. At $870{ }^{\circ} \mathrm{C}$, the difference in oxidation attack between the two alloys is not as significant.

Table II. Isothermal rate constants for Nimonic 90 and Pyromet 751 at $870{ }^{\circ} \mathrm{C}$ and $930{ }^{\circ} \mathrm{C}$

\begin{tabular}{|c|c|c|}
\hline \multirow{2}{*}{ Temperature } & \multicolumn{2}{|c|}{ Isothermal Rate constants, $\mathrm{K}_{\mathrm{p}}\left(\mathrm{g}^{2} \mathrm{~cm}^{-4} \mathrm{~s}^{-1}\right)$} \\
\cline { 2 - 3 } & Nimonic 90 & Pyromet 751 \\
\hline \hline $870^{\circ} \mathrm{C}$ & $2.0 \times 10^{-13}$ & $2.0 \times 10^{-13}$ \\
\hline $930^{\circ} \mathrm{C}$ & $6.0 \times 10^{-12}$ & $2.0 \times 10^{-12}$ \\
\hline
\end{tabular}

While characterization of the oxide scales were performed at all times and temperatures of exposure, the SEM micrographs of samples exposed at $870{ }^{\circ} \mathrm{C}$ and $930{ }^{\circ} \mathrm{C}$ for the longest duration i.e., 500 hours have been included in this manuscript. Figure 4 
shows a SEM micrograph of Nimonic 90 after an exposure at 870 ${ }^{\circ} \mathrm{C}$ for 500 hours. A retained scale is observed along with some intergranular oxidation. Certain locations showed internal oxidation, with oxidation cracks extending through the internal oxidation region. Figure 5 is a micrograph of Nimonic 90 after an exposure at $930{ }^{\circ} \mathrm{C}$ for 500 hours exhibiting a dense retained scale, along with internal oxidation, with cracks extending through the internal oxidation zone. A comparison of Figure 4 and Figure 5 shows the denser scale formed in Nimonic 90 after exposure at $930{ }^{\circ} \mathrm{C}$ for 500 hours

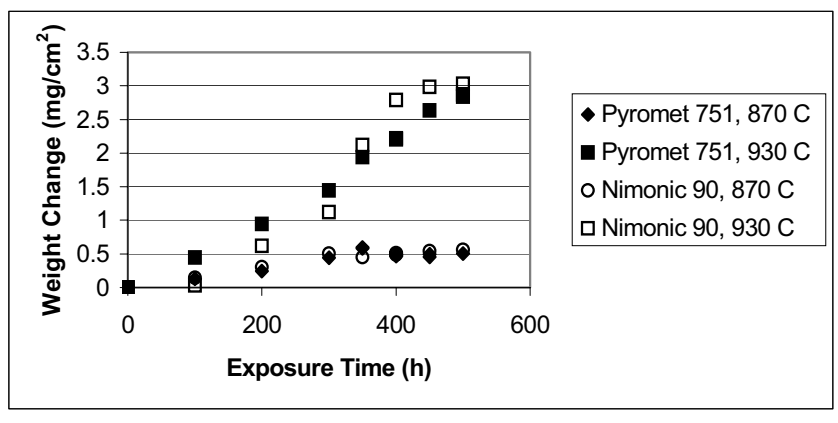

Figure 2 - Weight change during isothermal oxidation of Nimonic 90 and Pyromet 751 alloys at $870{ }^{\circ} \mathrm{C}$ and $930{ }^{\circ} \mathrm{C}$

Exposure at $870{ }^{\circ} \mathrm{C}$ for 500 hours for Pyromet 751, as shown in Figure 6, resulted in scale formation that was less dense compared to Nimonic 90 exposed under identical conditions. However, features such as intergranular oxidation and cracks through the internal oxidation zone appear to be similar for both the alloys. The extent of intergranular oxidation appears to be less in Pyromet 751. In Pyromet 751, a denser scale appeared after exposure at $930{ }^{\circ} \mathrm{C}$ for 500 hours as shown in Figure 7. Some amount of intergranular oxidation is observed.

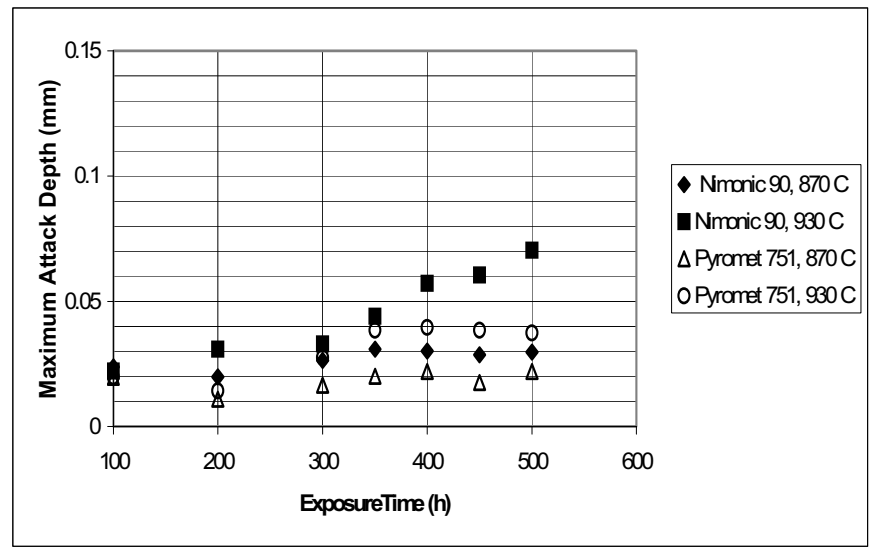

Figure 3 - Maximum attack depth measured during isothermal oxidation of Nimonic 90 and Pyromet 751 alloys at $870{ }^{\circ} \mathrm{C}$ and $930{ }^{\circ} \mathrm{C}$

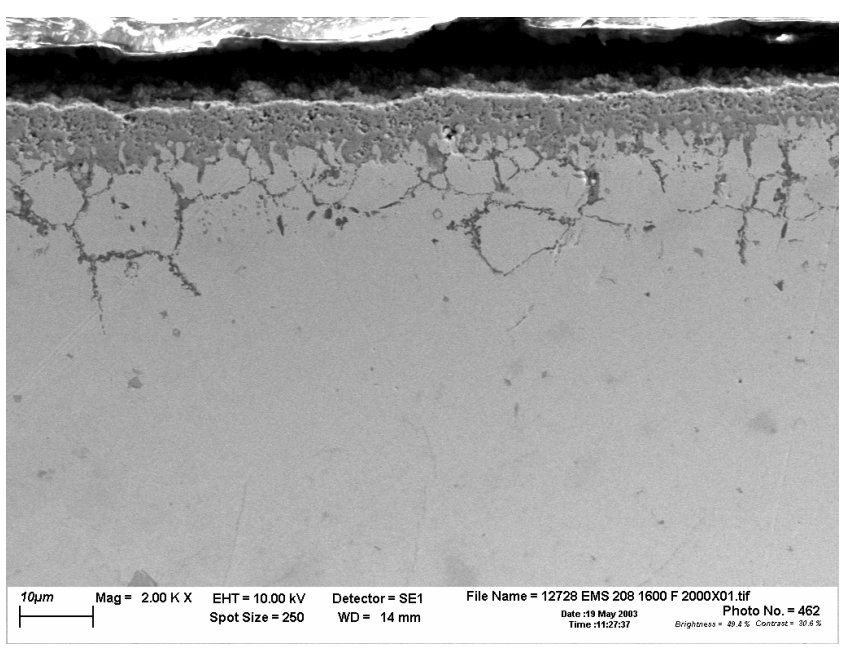

Figure 4 - SEM micrograph (2KX) of Nimonic 90 at $870{ }^{\circ} \mathrm{C}$ after 500 hours exposure

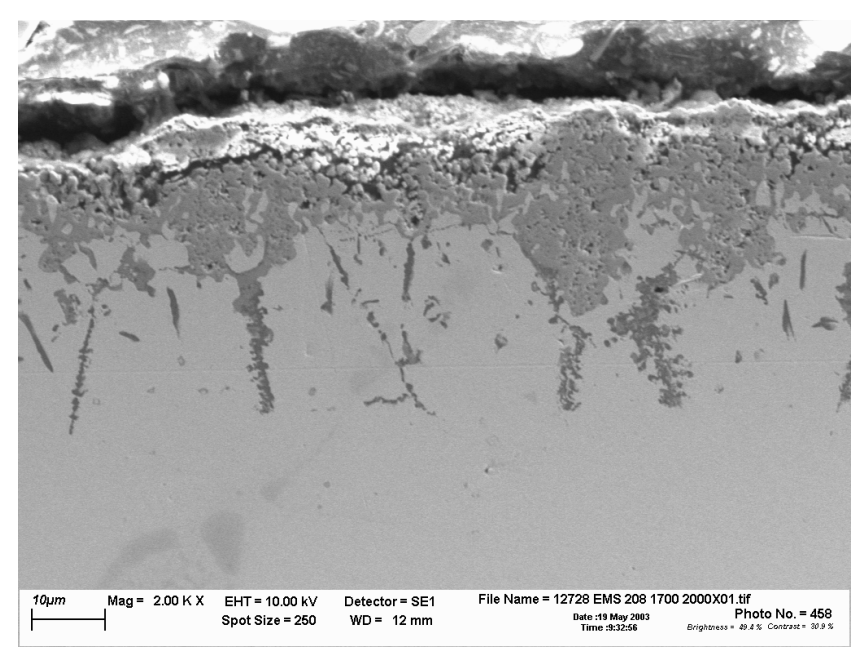

Figure 5 - SEM micrograph (2KX) of Nimonic 90 at $930{ }^{\circ} \mathrm{C}$ after 500 hours exposure

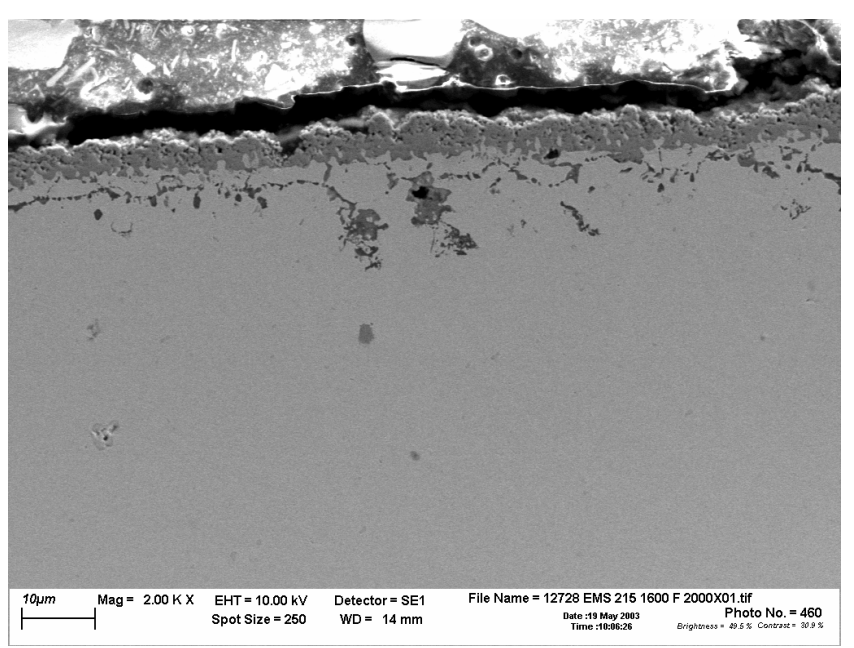

Figure 6 - SEM micrograph $(2 \mathrm{KX})$ of Pyromet 751 at $870{ }^{\circ} \mathrm{C}$ after 500 hours exposure 


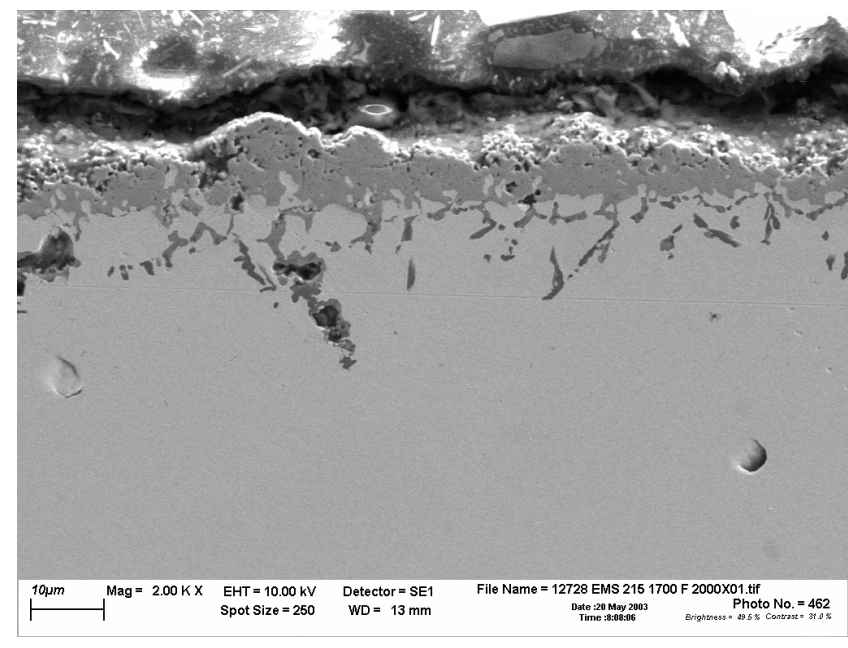

Figure 7 - SEM micrograph (2KX) of Pyromet 751 at $930{ }^{\circ} \mathrm{C}$ after 500 hours exposure

Effects of multi-element variations on high temperature oxidation of superalloys have been studied extensively by Smialek and Barrett and previous attempts to rank superalloys on oxidation resistance have been made ${ }^{[8,9,10,11]}$. Though broad trends of the effects of tantalum, titanium and a few other refractory elements on oxidation are possible, the complexity involved in discerning a clear effect of systematic variation of these elements on oxidation is quite challenging. The alloying content of Nimonic 90 and Pyromet 751 are very similar with respect to chromium, titanium and aluminum. Inspection of Table I shows that the significant difference between the alloys is that Nimonic 90 has more cobalt, but less tantalum and niobium. The presence of a substantial amount of cobalt, approximately 18 weight percent, is an important consideration for the higher oxidation of Nimonic 90 at $930{ }^{\circ} \mathrm{C}$, as the presence of cobalt in nickel-base alloys is thought to degrade oxidation resistance. This is consistent with the generally inferior oxidation resistance of cobalt-base alloys compared to nickel-base alloys ${ }^{[11]}$. The role of niobium and tantalum in the oxidation resistance of Pyromet 751 is unclear at the present. Niobium can have beneficial or deleterious effects on oxidation resistance, depending on alloying content in the superalloy ${ }^{[11]}$. Tantalum is considered as an effective booster of cyclic oxidation resistance in superalloys ${ }^{[11]}$ and is often a preferred refractory addition in superalloys for oxidation resistance ${ }^{[12]}$. It does appear that the presence of cobalt and its substitution for nickel could negate the beneficial effects of chromium on the oxidation resistance of Nimonic 90 at $930{ }^{\circ} \mathrm{C}$.

\section{Conclusions}

Two nickel-base superalloys for exhaust valve applications in spark-ignited engines and diesel EGRs have been compared for their oxidation behavior. The main conclusions from this study of Nimonic 90 and Pyromet 751 are as follows:

1. Oxidation behavior of Nimonic 90 and Pyromet 751 are influenced significantly by the temperature of exposure in the range of $870{ }^{\circ} \mathrm{C}$ and $930{ }^{\circ} \mathrm{C}$ for up to 500 hours of static air oxidation

2. Both the alloys exhibit similar oxidation behavior and oxide formation kinetics at $870{ }^{\circ} \mathrm{C}$. Based on optical microscopy, SEM/EDX spectroscopy characterization along with oxidation rate constant determination, the oxidation behavior of both these alloys followed $\mathrm{Cr}_{2} \mathrm{O}_{3}$ formation kinetics

3. Oxidation indicated especially by attack depth evaluation, increased significantly at $930{ }^{\circ} \mathrm{C}$ for both the alloys. Oxidation penetration was more intense in Nimonic 90 compared to Pyromet 751 at this temperature. It is apparent that substitution of cobalt for nickel in Nimonic 90 contributed to increased oxidation at $930{ }^{\circ} \mathrm{C}$

4. From an oxidation standpoint, Pyromet 751 can be expected to perform as well as Nimonic 90 at $870{ }^{\circ} \mathrm{C}$. However, it is possible that higher operating stress levels and the need for hot corrosion resistance may dictate the need for Nimonic 90 .

\section{Acknowledgements}

We acknowledge the metallurgical laboratory support provided by Mr. Terry Saylor and Mr. Ed Hurlbert of the Materials and Process Development Group at Eaton Corporation, Engine Air Management Operations. We also appreciate the helpful feedback and comments provided by Sandra Schaefer of Eaton Corporation.

\section{References}

1. J. M. Larson and L. F. Jenkins: "Application of Superalloys in Internal Combustion Engine Exhaust Valves", MiCon 78, ASTM STP 672, H. Abrams et al, eds., ASTM, 1979, pp. $578-600$

2. S. K. Schaefer, J. M. Larson, L. F. Jenkins and Y. Wang: "Evolution of Heavy Duty Engine Valves - Materials and Design", Proceedings of the International Symposium on Valvetrain System Design and Materials, H. A. Bolton et al, eds., ASM, 1997, pp. 129-139

3. M. Khobaib and F. W. Vahldiek: "Oxidation Behavior of Advanced Ni-base Single Crystals", Corrosion and Particle Erosion at High Temperatures, V. Srinivasan et al, eds., TMS, 1989, pp. 515-530

4. H. Hindram and D. P. Whittle: Oxidation of Metals, Vol. 18 (Nos. 5/6), 1982

5. S. J. Balsone and M. Khobaib: $2^{\text {nd }}$ International SAMPE Metals Conference, 1988

6. C. S. Giggins and F. S. Pettit: J. Electrochem. Soc., 118 (1971). P. 1782

7. C. S. Giggins and F. S. Pettit, "Oxide Scale Adherence Mechanisms and the Effects of Yttrium, Oxide Particles and Externally Applied Loads on the Oxidation of NiCrAl and CoCrAl alloys," ARL-TR-75-9234, 1975

8. C. A. Barrett, R. V. Miner and D. R. Hull, Oxidation of Metals, 516, 255 (1983)

9. C. A. Barrett, NASA TM-83784, 1984

10. J. L. Smialek and G. H. Meier, "High Temperature Oxidation", Superalloys II: High Temperature Materials for Aerospace and Industrial Power, C. T. Sims et al, eds., J. Willey, 1987, pp. 293-326

11. C. A. Barrett, R. G. Garlick and C. E. Lowell, NASA TM83865,1984

12. C. T. Sims, F. S. Pettit and G. H. Meier, Refractory Alloying Elements in Superalloys, J. K. Tien and S. Reichman, eds., ASM, Metals Park, OH, 1984, p.165 